\title{
Attending to mathematics teacher thinking
}

\author{
Olive Chapman ${ }^{1}$
}

Published online: 16 January 2017

(C) Springer Science+Business Media Dordrecht 2017

Attention to teacher thinking and its relationship to effective teaching continues to be an important aspect of research on the mathematics teacher and ongoing efforts to reform mathematics education. Teacher thinking is a significant variable in the educational equation. It profoundly influences teachers' behaviors and students' experiences in the classroom. It embodies a teacher's way of making sense of what she/he does and why and how he/she does what she/he does. Thus, understanding mathematics teaching from a classroom or practice-based perspective necessitates understanding mathematics teachers' thinking regarding the mathematics they teach, their instructional approaches, and their students' learning. This requires focusing not on what teachers should be doing but rather on what they are already doing and why. Understanding how to meaningfully support teachers' learning also requires understanding and attending to their thinking. Thus, research on mathematics teaching and teacher learning needs ongoing focus on the more subtle and implicit aspects of teaching associated with teacher thinking to increase our knowledge of these two areas of mathematics education.

This issue of the Journal of Mathematics Teacher Education consists of four articles that directly or indirectly contribute insights regarding different aspects of mathematics teachers' thinking. They attend to examples of the nature and role of teacher thinking rather than on a pre-defined disposition of teacher knowledge. Jinfa Cai and Meixia Ding's article focuses on practicing teachers' views of mathematical understanding and teaching to achieve it; Andreas Eckert and Per Nilsson's article considers practicing teachers' interpretations of mathematical objects; Mathew Felton-Koestler's article reports on prospective teachers' views of social and political dimensions of mathematics teaching and learning; and Charity Cayton, Karen Hollebrands, Samet Okumus, and Ethan Boehm's article reports on practicing teachers' actions and questions. Each of the articles provides a different way of making sense of mathematics teacher thinking as highlighted in the following summaries of them.

Olive Chapman

chapman@ucalgary.ca

1 University of Calgary, Calgary, Canada 
Cai and Ding's study investigated experienced Chinese teachers' views on the meaning of mathematical understanding and ways to achieve it. Participants were 61 mathematics teachers from a summer workshop. They had national or local reputations for excellence in teaching mathematics. Their expertise covered the lower, middle, and upper elementary grades. Each of the teachers was asked to provide free written responses to three openended questions regarding their views without time limitations. Findings indicated that the teachers' views of mathematical understanding contained richer relationships than the relationships between concepts and procedures in the literature. They viewed mathematical understanding as an integration of concepts and procedures with "concept" being the core of a web of connections. This included hierarchical representational connections within a concept (e.g., from concrete to abstract), connections between concepts and procedures and between concepts and concepts, and connections between examples and a concept, between examples and non-examples, and between examples and situations. The teachers placed emphasis on the process that leads to the product, for example, understanding a concept includes a process of initial development, revisiting the concept directly, and revisiting the concept in context. Most of the teachers viewed the use of concrete modeling (e.g., hands-on work, drawing, and using real-life situations) in relation to the initial concept development stage, which is aligned with the perspective that mathematics learning is guided reinvention where students progressively mathematize informal and concrete knowledge into formal and abstract knowledge. The teachers considered it important to provide various opportunities for students to develop implicit knowledge through analogical reasoning, including evaluation of performance (or judging tasks involving "relational comparisons") and transfer problems. They purposefully chose examples and non-examples that appeared confusing and prompted students to compare, explain, and justify. They also viewed verbal statements of concepts, principles, and definitions as important, which indicated their attention to explicit knowledge. Students' own explanations were viewed as critical for enhancing learning from both examples and problem solving.

Eckert and Nilsson's study investigated teachers' patterns of interaction as they negotiated the meaning of experimentally based concepts of probability in their teaching. The study, framed in a symbolic interactionism perspective of teaching, focused on how teachers used revoicing as a discursive tool in teaching mathematics. Revoicing involves the re-uttering of students' mathematical explanations. In relation to teacher thinking, one of the research questions addressed the roles teachers' interpretations of probability concepts played in negotiating these concepts in student interaction. Participants were two teachers who had several years of experience teaching mathematics at the elementary school level, but neither had any experience teaching probability theory. A series of lessons taught by the teachers at a public primary school in Sweden were video recorded. The fifthand sixth-grade students involved had no previous formal instruction in probability theory. The lessons discussed in the article focused on negotiations of the meaning of chance. Findings included that the teachers interpreted chance both colloquially (i.e., an informal use of the concept, grounded in everyday language) and mathematically (i.e., as a random variable) when interacting with their students. They interpreted chance in both ways during the lessons, and their different interpretations impacted the negotiation processes. Their actions were based on how they perceived the interactions and interpreted the meaning of the concepts of chance and probability. Revoicings based on interpretations made by the two teachers formed an interaction strategy that directed the negotiation of meaning. Active revoicings provided the students with more information about the object under investigation by indicating the teachers' interpretations. Whether an active revoicing was 
based on a colloquial or mathematical interpretation of chance, it played an important role in the continuation of the discussions. Inactive revoicings did not indicate the teachers' interpretations or intentions to the students, which shut down some of the students' ideas and thus limited their opportunities to express alternative views.

Felton-Koestler's study investigated a framework he developed by exploring his teaching of prospective teachers and their views of the social and political dimensions of mathematics teaching and learning. The "What, Who, How" framework focuses on the relationship between the content of school mathematics and "the world" with each aspect of the framework situated in the literature on social justice and critical mathematics. The "What" deals with the messages teachers send about the co-constructed nature of school mathematics and the role of social analysis in school mathematics. The "Who" deals with whose perspectives are represented in school mathematics. The "How" deals with the relationship between school mathematical concepts and the "real world." Fifty-five prospective teachers at the elementary school level were students in the researcher/instructor mathematics courses designed for them at two institutions in the USA. Findings regarding the prospective teachers' views for each component of the framework include the following. For the "What," while some prospective teachers agreed with mathematics as co-constructed, others expressed some level of resistance to it, for example, claiming that there is no longer a need to attend to issues of inequity in mathematics. While most of them embraced the idea that mathematics is "everywhere" many avoided overt sociopolitical connections. For the "Who," some of the prospective teachers rejected the notion that people may experience mathematics differently based on their identity (i.e., viewing mathematics as universal). However, many of them, either explicitly or implicitly, supported the idea that mathematics may be experienced differently by learners (i.e., viewing mathematics as personal). For the "How," they rarely made explicit statements about how the world and mathematical concepts should be related. Regarding the kinds of mathematical tasks that they suggested for use in the classroom, they frequently emphasized focusing on mathematical concepts, with very few examples of a substantive, authentic focus on the world. Many of them argued that mathematics teaching should focus primarily on concepts, often suggesting that some real-world context can be enriching, as long as it does not interfere with "the mathematics." Others took a stronger stance that mathematics should remain separate from real-world contexts.

Cayton et al.'s study examined teachers' actions and questions during "pivotal teaching moments" to characterize mathematics instruction that utilizes technology. The focus was on the ways teachers responded to pivotal teaching moments in technology-intensive secondary school geometry classrooms associated with teacher-student interactions (e.g., actions, statements, questions) that occurred during these moments to determine how they may be related to teacher-tool relationships. The authors cite Stockero and Van Zoest's (2013) definition of pivotal teaching moments as "an instance in a classroom lesson in which an interruption in the flow of the lesson provides the teacher an opportunity to modify instruction in order to extend or change the nature of students' mathematical understanding" (p. 127). The study focused on three of 24 teachers who participated in the geometry cohort of a larger professional development project in the USA. Their participation included a two-week-long summer institute and 2 years of online professional development with classroom-level support. They used a dynamic geometry program (The Geometer's Sketchpad) in their high school geometry classes over the two years. Findings indicated that one teacher used the technology as "Servant" to emphasize mathematical meaning and relationships when responding to pivotal teaching moments by asking highlevel questions. Another used it as "Partner" to pursue student thinking with high-level 
questions. The third teacher used it as "Master" which coincided with her predominant action to repeat technology directions and ask procedural/factual questions. The teachertool relationship for each teacher aligned with his/her preference for responding to pivotal teaching moments and her/his use of questioning supported his/her responses to pivotal teaching moments. The "partner" teacher posed more non-procedural/factual questions and allowed students to use the technology to explore mathematics. He mostly asked probing and other high-level questions that revealed students' thinking and provided students with opportunities to clarify and elaborate their thinking. The other two teachers did not ask many questions of these types and were not as effective in supporting, eliciting, and extending students' mathematical thinking.

The four articles suggest different ways of describing teacher thinking. In Cai and Ding's study, it occurs as practicing teachers' views, in Felton-Koestler's study, as prospective teachers' views, in Eckert and Nilsson's study, as practicing teachers' interpretations, and in Cayton et al.'s study, as practicing teachers' preferences. The studies also offer examples of different aspects of teacher thinking, mathematics, and teaching. Cai and Ding's study provides a practice-based perspective of the meaning of mathematical understanding as a web of connections resulting from continuous connection making and ways to achieve mathematical understanding that include reinventing a concept, verbalizing a concept, and using examples and comparisons for analogical reasoning. Eckert and Nilsson's study provides an example of how teachers' different interpretations of subject matter can impede or support the joint enterprise of meaning-making through negotiation. Felton-Koestler's study provides an example of a framework consisting of the What, Who, How of mathematics that can be used as a tool to understand prospective teachers' views and a means of informing the practice of teachers and teacher educators. Cayton et al.'s study provides an example of the relationship between teachers' preferences for responding to pivotal teaching moments and teacher-tool connection and an example of the use of metaphors (i.e., servant, partner, master) that embodies teacher thinking regarding their behavior during teacher-student interactions when using a dynamic geometry program.

These studies draw our attention to specific aspects of teacher thinking and the importance of researching it in relation to understanding mathematics teaching. However, research consideration is also needed of how teacher thinking is being integrated in teacher education and professional development to support teachers' learning and change.

\section{Reference}

Stockero, S. L., \& Van Zoest, L. R. (2013). Characterizing pivotal teaching moments in beginning mathematics teachers' practice. Journal of Mathematics Teacher Education, 16(2), 125-147. 